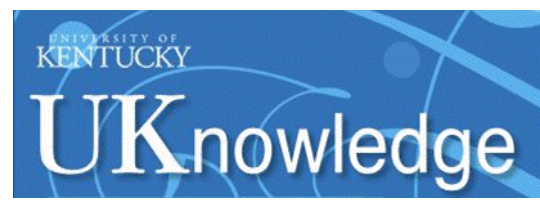

University of Kentucky

UKnowledge

Theses and Dissertations--Public Health (M.P.H.

\& Dr.P.H.)

College of Public Health

2015

\title{
Healthcare Industry Injuries by Patient Contact Status in Kentucky, 2012-2014
}

Kristen Ranzenberger

University of Kentucky

Follow this and additional works at: https://uknowledge.uky.edu/cph_etds

Part of the Public Health Commons

Right click to open a feedback form in a new tab to let us know how this document benefits you.

\section{Recommended Citation}

Ranzenberger, Kristen, "Healthcare Industry Injuries by Patient Contact Status in Kentucky, 2012-2014" (2015). Theses and Dissertations--Public Health (M.P.H. \& Dr.P.H.). 61.

https://uknowledge.uky.edu/cph_etds/61

This Graduate Capstone Project is brought to you for free and open access by the College of Public Health at UKnowledge. It has been accepted for inclusion in Theses and Dissertations--Public Health (M.P.H. \& Dr.P.H.) by an authorized administrator of UKnowledge. For more information, please contact UKnowledge@lsv.uky.edu. 


\section{STUDENT AGREEMENT:}

I represent that my capstone and abstract are my original work. Proper attribution has been given to all outside sources. I understand that I am solely responsible for obtaining any needed copyright permissions. I have obtained needed written permission statement(s) from the owner(s) of each third-party copyrighted matter to be included in my work, allowing electronic distribution (if such use is not permitted by the fair use doctrine) which will be submitted to UKnowledge as Additional File.

I hereby grant to The University of Kentucky and its agents the irrevocable, non-exclusive, and royalty-free license to archive and make accessible my work in whole or in part in all forms of media, now or hereafter known. I agree that the document mentioned above may be made available immediately for worldwide access unless an embargo applies.

I retain all other ownership rights to the copyright of my work. I also retain the right to use in future works (such as articles or books) all or part of my work. I understand that I am free to register the copyright to my work.

\section{REVIEW, APPROVAL AND ACCEPTANCE}

The document mentioned above has been reviewed and accepted by the student's advisor, on behalf of the advisory committee, and by the Director of Graduate Studies (DGS), on behalf of the program; we verify that this is the final, approved version of the student's capstone including all changes required by the advisory committee. The undersigned agree to abide by the statements above.

Kristen Ranzenberger, Student

Terry Bunn, PhD, Committee Chair

Dr. Linda Alexander, Director of Graduate Studies 


\title{
Healthcare Industry Injuries by Patient Contact Status
}

in Kentucky, 2012-2014

\author{
Capstone Project Paper
}
A paper submitted in partial fulfillment of the
Requirements for the degree of
Master of Public Health
in the
University of Kentucky College of Public Health
By
Kristen Ranzenberger, DO
Lexington, Kentucky

Lexington, Kentucky

October 29, 2015

Terry Bunn, PhD, Chair

David Mannino, MD

T. Scott Prince, MD, MPH 


\section{Abstract}

Objectives: The healthcare industry continues to have a high number of reported injuries. The purpose of this study was to 1) characterize healthcare industry injuries by patient contact status; 2) identify the occupations associated with healthcare injuries by patient contact status; and 3) determine healthcare injury rates by occupation, to gain a better understanding of healthcare industry compensated injuries, and better target healthcare industry safety practices and programs.

\section{Methods}

Workers' Compensation first reports of injuries (FROI) from the healthcare industry in Kentucky were categorized into injuries involving in direct patient contact vs. injuries without direct patient contact using narrative text analysis. Injury numbers and rates were calculated for a number of data variables.

\section{Results}

Among 11,204 FROls analyzed, 45\% were determined to involve direct patient contact. Sprain injuries accounted for the majority of injuries $(5,671) ; 66 \%$ of sprain injuries involved direct patient contact. Healthcare support staff had the highest incidence rate for reported injuries at 32.2 per 1000 support staff employees in 2013. The highest number of direct patient contact injuries occurred in nursing care facilities. General medical and surgical hospitals were locations of most injuries without direct patient contact.

\section{Conclusion}

Study findings can be used to increase awareness for Kentucky healthcare workers' safety. While patient care is a risk factor associated with injury, our study shows that 
many injuries occur outside the scope of direct patient care. It's important to understand the work elements in the healthcare industry to target prevention strategies and provide a safe work environment. 


\section{Introduction}

Healthcare in the United States has made great strides over the years in improving the quality of patient care and safety. Hospitals and other care facilities are geared toward helping ill and injured patients heal, as well as making advances toward a better quality of life for patients [1]. Ironically, the healthcare industry has one of the highest injury rates for employees in the private sector [2] compared to all other private industries in the U.S. According to the Bureau of Labor Statistics (BLS), the number of work related injury and illness cases in the healthcare and social services industry was reported at 653,900 in 2010 , which was the highest among all private sector industries in that year [2]. Within the healthcare industry in the U.S., hospitals, followed by nursing and residential care facilities, had the greatest numbers of reported injuries and illnesses at 258,200 and 202,300 , respectively [2]. Healthcare is a multifaceted industry with a wide range of job hazards including "bloodborne pathogens and biological hazards, potential chemical and drug exposures, waste anesthetic gas exposures, respiratory hazards, ergonomic hazards from lifting and repetitive tasks, laser hazards, workplace violence, hazards associated with laboratories, and radioactive material and x-ray hazards." [3]. Aside from workers directly involved with patient care, there are many non-clinical occupations within the healthcare setting such as food services, housekeeping, laundry services, building and grounds maintenance, and administrative and clerical positions. Both clinical and non-clinical positions have unique job descriptions, which come with associated risks of injuries and exposures.

Musculoskeletal injuries are the leading cause of healthcare worker injuries. Research shows that patient handling is one of the biggest risk factors for acquiring 
musculoskeletal disorders [4, 5]. In 2013, the healthcare and social assistance sector reported an incidence rate of 50.2 reported injuries per 10,000 full-time workers for musculoskeletal disorders, which is second only to the transportation and warehousing industry [6]. Needle-stick and other sharps-related injuries are commonly reported in the healthcare industry, as well. According to the Centers for Disease Control and Prevention (CDC), approximately 385,000 sharps injuries are reported on an annual basis in the US [7]. In the hospital setting, sharps injuries occurring during instrument use account for $48 \%$ of sharps injuries, while those occurring after instrument use but prior to instrument disposal account for $30 \%$ of sharps injuries $[7,8]$. Sharps injuries are not exclusive to physician and nursing positions. Studies have found that housekeeping staff involved in waste removal and home care aides often acquire needle sticks due to improper disposal of used equipment $[8,9]$.

A great deal of research has been done on healthcare worker injuries, but no studies characterize and describe healthcare industry compensated injuries by patient contact status. The purpose of this study was to 1) characterize healthcare industry injuries by patient contact status; 2) identify the occupations associated with healthcare injuries by patient contact status; and 3) determine healthcare injury rates by occupation, to gain a better understanding of healthcare industry compensated injuries and better target healthcare industry safety practices and programs.

\section{Methods}

The Kentucky Department of Workers' Claims (KDWC) maintains reported injury data for all Kentucky industries, except for those under exempt status including farm workers, self-employed workers, and employees covered under federal policies. The 
first report of injury (FROI) forms are typically completed by an employer representative and sent to KDWC by the Workers' Compensation insurance carrier. Employer Standard Industrial Codes (SICs) or North American Industry Classification System (NAICS) codes are identified on the FROI form, indicating the employment industry of the injured employee.

FROls included all initial reports of injuries reported in calendar years 2012-2014. The FROI data include data variables such as demographic variables, nature of injury, cause of injury, body part injured, date of injury occurrence, county of injury occurrence, type of facility where the injury occurred, and a detailed description of how the injury occurred in narrative free text format. The nature of injury was divided into eight categories: sprain (sprains, strains, tears), fracture, laceration (including puncture wounds), contusion, burn, multiple injuries, other (exposures to pathogens or chemicals, psychological stress, inhalation), injury not specified, and no physical injury. Cause of injury was grouped into nine categories: lifting (injuries occurring while lifting or handling), fall (falls, slips, trips), motor vehicle accident, struck by person, struck by object or animal, caught in something, no physical injury (exposure to chemicals or pathogens), and cause not specified. The struck by object and struck by animal categories were combined into one category due to low reporting numbers. Body part injured was separated into ten categories: head (including face), neck, back, trunk, upper extremity (shoulder, upper arm, fore arm, wrist, hand, fingers), lower extremity (hip, thigh, knee, leg, ankle, foot, toes), multiple body parts, non-musculoskeletal (injuries to internal organs, psychological injuries), no physical injury, injury not identified. FROIs that indicated 'no physical injury' in any category were not excluded 
because submission of $\mathrm{FROI}$ forms suggest a medical provider was consulted and a Workers' Compensation claim was generated, regardless of the outcome.

Review of FROI narrative text was conducted to determine if the injury involved direct patient contact. Direct patient contact was defined as an incident where the employee was physically touching or performing a procedure on the patient at the time of injury occurrence, or the patient's actions resulted in an injury to the employee. If the detailed description did not disclose whether or not direct patient contact was involved, the FROI was categorized as undetermined. Demographic information included gender, age, and occupation of the injured employee. For the FROIs that did not have a recorded occupation, the occupation was determined by physician review of the detailed injury narrative text. If the injury narrative text did not identify the occupation, the record was categorized as an unknown occupation.

The FROI data was classified into direct patient contact or non-direct patient contact involvement, regardless of the worker's job title. Occupations were grouped into 5 separate categories: 1) Clinical workers; 2) community and social service type workers (social workers, mental rehabilitation counselors, chaplains, youth counselors); 3) administrative or office workers; 4) other (non-patient oriented occupations including kitchen staff, building maintenance, housekeeping, etc.); and 5) unknown. The clinical worker category was divided into four subcategories based on education level: 1) practitioners including physicians, dentists, physician assistants, nurse practitioners, nurse anesthetists, nurse midwives, pharmacists, chiropractors, speech pathologists, and physical and occupational therapists; 2) nurses including registered nurses, licensed practical nurses, licensed vocational nurses; 3) technical support staff including 
radiology technicians, surgical technicians, emergency medical technicians and paramedics, laboratory assistants, phlebotomists, and physical and occupational

therapy assistants; and 4) healthcare support staff including certified nursing assistants, direct care professionals, home health aides, medical assistants, mental health assistants, resident assistants, personal care assistants, state registered nursing aides, and patient transporters. Non-clinical occupation categories were not subcategorized.

Frequencies were determined and chi-square tests were performed to assess the differences between healthcare injuries involving direct patient contact vs. healthcare injuries without direct patient contact. Data analysis was performed using Statistical Analysis Software (SAS). The incidence rates for the KDWC claims for the clinical occupations were estimated using full time equivalents (FTEs) as the denominator from state occupational employment estimates in Kentucky for 2012-2014 [10]. According to the Medical Institutional Review Board for the University of Kentucky, this study met the criteria for an exempt study, and an IRB was not required.

\section{Results}

A total of 12,254 healthcare industry FROls were identified from KDWC. Among the 12,254 FROIs reviewed, 265 duplicate FROIs, 188 FROIs with occupations identified as 'day care workers', and 597 FROls where direct patient contact could not be determined were excluded from the study; there were 11,204 final FROls analyzed for the study. The majority of all healthcare industry injuries (55\%) did not involve direct patient contact $(n=6,145 ; p=<.0001$; Table 1$)$. Overall, females comprised $86 \%$ of the 11,142 total FROI cases. Females had a higher percentage of healthcare injuries involving direct patient contact vs. those without direct patient contact. In contrast, 
males had a higher percentage of injuries without patient contact compared to males with direct patient contact. Those younger than 35 years of age $(n=4,146)$ had higher percentages of injuries involving direct patient contact compared to young healthcare workers under 35 years of age without direct patient contact. The highest percentage of injuries with direct patient contact was among healthcare workers aged 25-34, whereas the highest percentage of injuries without direct patient contact was among older healthcare workers aged 45-54. The healthcare support occupation had the highest total number of injuries regardless of patient contact status. Even though nurses only made up $17 \%$ of all direct patient contact injuries $(5,059), 51 \%$ of all nursing injuries involved direct patient contact $(n=1,669)$. Other occupations without direct patient contact such as housekeepers, kitchen staff, and maintenance workers had a higher percentage of injuries without direct patient contact compared to the other occupations with direct patient contact. Out of 11,204 records, $21 \%$ of occupations could not be determined.

Figure 1 shows the reported injury rates for the clinical occupations. Healthcare support occupations had significantly higher injury rates, more than double the injury rates reported by nurses. In 2013, the incidence rate was 32.3 reported injuries per 1000 employed healthcare support workers in Kentucky. Nurses had the next highest rate at 12.1 reported injuries per 1000 employed nurses in that same year. Healthcare practitioners had the lowest rates at only 2.6 injuries per 1000 employed healthcare practitioners for 2013. Reported injury rates did not change over the three year period. 
There was a spike in reported rates in 2013, but overall there was no increase or decrease in reported cases.

Sprain injuries made up $51 \%$ of all injuries irrespective of patient contact status (Table 2). Strain and tears were more frequent injuries among healthcare workers with direct patient contact compared to those healthcare workers without direct patient contact. There were higher percentages of fractures, lacerations, and contusions among healthcare industry workers without direct patient contact compared to healthcare industry workers with direct patient contact.

The highest percentage of injuries involving direct patient contact were lifting/handling related injuries, whereas falls/slips/trips accounted for the highest percentage of injuries in healthcare workers without direct patient contact. Among healthcare workers involved in direct patient contact, lifting (52\%), struck by person $(17 \%)$, and struck by object or animal injuries were the leading injury classifications. In contrast, leading injuries for healthcare workers without direct patient contact were primarily falls (39\%), followed by struck by object or animal (19\%), and by lifting injuries (17\%). Back injuries were more common among healthcare workers with direct patient contact vs. those without direct patient contact. In comparison, lower extremity and multiple body part injuries were more commonly reported in healthcare workers without direct patient contact.

Looking at the facility where injury occurred, general Medical and Surgical Hospitals, and practitioner offices had the highest percentages of injuries (34\% and $10 \%$, respectively) not involved in direct patient contact compared to those with direct patient contact (28\%, and $6 \%$, respectively) (Table 3$)$. In contrast, there were a higher 
percentage of injuries involving direct patient contact in nursing care facilities (39\%) compared to healthcare worker injuries without direct patient contact. There was no difference between the patient contact groups in regards to region of injury occurrence (Appalachian vs. non-Appalachian regions). A higher percentage of injuries occurred in October for those healthcare workers with direct patient contact vs. those without direct patient contact.

\section{Discussion}

While many studies have been performed on healthcare worker injuries, this is the first study, to the authors' knowledge, of FROI data analysis of injuries by patient contact status for both clinical and non-clinical occupations within the healthcare industry. Overall, we found that the majority of injuries among all healthcare workers did not involve direct patient contact. The healthcare injuries not involving patient contact were nearly equivalent between clinical and non-clinical occupations. Our study results are aligned with a case-control study that compared musculoskeletal injuries among maintenance, custodial, and direct care staff in two hospitals and showed that maintenance and custodial employees were more likely than direct caregivers to sustain strain injuries [11]. Worker safety needs to be addressed for each of the major occupational groups within healthcare systems.

Injuries among the youngest age group involved direct patient contact. There are a number of possible explanations for why young employees are injured during patient care. Young employees are typically in new or entry-level positions and these findings may indicate a learning curve for skill performance or inadequate training of new employees [12]. Alternatively, older workers may perform less physically demanding 
job activities. Mentoring of younger employees and creating ways to ensure young workers feel comfortable expressing concerns may to help reduce risks for younger employees.

Sprain injuries comprised the majority of all injuries in both patient and nonpatient contact categories. Lifting was the cause for the majority of injuries related to patient care. This study echoes findings from other sources. Among all injuries occurring in the healthcare setting, musculoskeletal disorders are the leading type of reported injury in the U.S., accounting for $44 \%$ of all healthcare injuries [13]. Musculoskeletal injuries account for a large number of workers' compensation claims in the U.S. $[4,5,14]$. Safe patient handling procedures need to continue to be emphasized in education and training programs. Patient lifting assists, including specialized lift teams and lifting equipment, are proven to be effective if utilized properly [5]. Healthcare-related facilities may need to examine policies and procedures to ensure patient and employee wellbeing. Creating a safe environment needs to be a continuous focus for both worker health and economic longevity.

Our study revealed that Healthcare support occupations have the highest injury rate of all occupations in the healthcare industry, consistent with other studies comparing nursing and nursing support staff injuries $[15,16]$. Since the majority of nursing support jobs are in nursing facilities and long-term care facilities [17], our study finding that most of the injuries involved in patient contact happened in nursing care facilities and continuing care retirement communities are not unexpected. Health practitioners had the smallest number and rate of injuries and may be under-reported. Many studies on sharps injuries focused on providers and nurses showed that doctors 
and nurses had the highest number of sharps injuries $[18,19]$. One study found that doctors had the highest rate of underreporting at $67 \%$ [18]. 'Lack of time to report the injury' and feeling that the injury was 'considered to be low risk', were identified factors for providers not reporting an incident [18]. While overall injuries occur more often among the healthcare support occupations, there appears to be a reporting disparity between the higher level of educated workers and lower level positions by educational attainment status.

Nearly all (96\%) of struck by person injuries involved direct patient contact. This study indicates that struck by person injuries, although few in number, may occur by persons other than a patient, such as co-workers, family members of patients, or bystanders. Violent acts in the workplace create stress in the environment, leading to decreased productivity for employees [6, 20]. The Bureau of Labor Statistics announced that violence rates involving health and social services workers are more than triple that of laborers in other private sectors in recent years [7]. One study investigating emergency department violence found a high prevalence of threats and physical assaults toward all employees in the emergency department [21]. It is crucial for employees to report violent events in order for facilities to be informed of issues and have methods in place to curtail violent events toward employees.

Falls (39\%) and struck by object or animal injuries (19\%) were the top two causes for injuries not involving patient contact. Fall injuries are common in all work industries and comprise a large portion of work related injuries treated in emergency departments annually $[6,20]$. This study demonstrates that healthcare workers are not immune to fall injuries. Implemented fall prevention plans and strategies have been 
effective in reducing falls [20] and there continues to be a need to address fall prevention.

\section{Limitations}

This was a cross-sectional study using previously collected data, which prevented the ability to further clarify narrative text information about injury details which could have influenced frequencies observed per occupational group. Severity of the reported injuries was not included in this data, which inhibited the ability to observe differences in severity of injuries among occupational groups. There is also the possibility of recall bias from the worker reporting the injury although this is unlikely since injuries should be reported immediately to their supervisors. Misclassification bias due to second hand parties completing FROI forms is also possible. Last, there could have been differential injury reporting rates for the different occupations, which may influenced results.

\section{Conclusion}

The study findings from this analysis help identify the specific occupations and facility types where workers are being injured in the healthcare sector. Our study shows that injuries in healthcare were not limited to workers strictly involved in patient care. In this analysis, we also found that a high percentage of patient related injuries were among younger workers. Targeting the younger workforce for enhanced education and training programs may be appropriate for improving the discrepancy among the age groups.

Healthcare support occupations reported the majority of injuries and long-term care facilities had the highest number of injuries for patient contact injuries; general 
medical and surgical hospitals had the majority of injuries not involved in direct patient contact. For injury control purposes, findings from this study can be helpful for healthcare facilities to understand what kind of injuries are occurring to better guide the establishment of intervention and training programs for both patient oriented and nonpatient oriented employees.

\section{Acknowledgements}

Thank you to Dr. Terry Bunn at Kentucky Injury Prevention and Research Center for guidance, encouragement, and obtaining the data. Thank you to Dr. Svetla Slavova for helping with statistical analysis. 
Table 1. Demographic characteristics of healthcare worker injuries by direct patient contact status, in Kentucky 2012-2014.

\begin{tabular}{|c|c|c|c|c|c|c|}
\hline \multirow{2}{*}{$\begin{array}{l}\text { Demographic } \\
\text { Characteristics }\end{array}$} & \multicolumn{2}{|c|}{$\begin{array}{l}\text { Healthcare injury } \\
\text { involving in direct } \\
\text { patient contact }\end{array}$} & \multicolumn{2}{|c|}{$\begin{array}{l}\text { Healthcare injury } \\
\text { without direct } \\
\text { patient contact }\end{array}$} & \multirow[t]{2}{*}{$\begin{array}{l}\text { Total } \\
\text { Injuries }\end{array}$} & \multirow{2}{*}{$p$-value ${ }^{a}$} \\
\hline & $\#$ & (\%) & $\#$ & (\%) & & \\
\hline Male & 593 & $(12)$ & 1040 & (17) & 1633 & $<.0001$ \\
\hline Female & 4447 & (88) & 5062 & (83) & 9509 & \\
\hline Total & 5040 & & 6102 & & 11,142 & \\
\hline \multicolumn{7}{|l|}{ Age (years) } \\
\hline$\leq 24$ & 1008 & (20) & 612 & (10) & 1620 & $<.0001$ \\
\hline $25-34$ & 1418 & (28) & 1108 & (18) & 2526 & \\
\hline $35-44$ & 1172 & (23) & 1271 & (21) & 2443 & \\
\hline $45-54$ & 941 & (19) & 1618 & (26) & 2559 & \\
\hline $45-54$ & 520 & (10) & 1536 & (25) & 2056 & \\
\hline $\begin{array}{l}55+ \\
\text { Total }\end{array}$ & 5059 & & 6145 & & 11,204 & \\
\hline \multicolumn{7}{|l|}{ Occupation $^{c}$} \\
\hline Clinical Services & & & & & & $<.0001$ \\
\hline Practitioners & 116 & $(2)$ & 89 & (1) & 205 & \\
\hline Nurses & 856 & $(17)$ & 813 & (13) & 1669 & \\
\hline Technical Support & 280 & (6) & 400 & (7) & 680 & \\
\hline Healthcare Support & 2513 & (50) & 1154 & (19) & 3667 & \\
\hline $\begin{array}{l}\text { Community and Social } \\
\text { Services }\end{array}$ & 149 & (3) & 231 & (4) & 380 & \\
\hline Administrative/Office & 33 & $(<1)$ & 438 & (7) & 471 & \\
\hline Other & 32 & $(<1)$ & 1706 & $(28)$ & 1738 & \\
\hline Undetermined & 1080 & $(21)$ & 1314 & $(21)$ & 2394 & \\
\hline Total & 5059 & & 6145 & & 11,204 & \\
\hline
\end{tabular}

${ }^{a} p$-value based on chi-square

${ }^{\mathrm{b}} 62$ records $(0.5 \%)$ had missing values for gender and were excluded from the analysis

'Occupation categories defined: Practitioners: physicians, physician assistants, nurse practitioners, nurse anesthetists, dentists, chiropractors, pharmacists, physical/occupational therapists; Nurses: registered nurse, licensed practical nurse, licensed vocational nurse; Technical support staff: dental hygienists, surgical technicians, radiology technicians, emergency medical technician, paramedics, pharmacy technologists, lab technicians, surgical technicians, dialysis technicians, respiratory therapists; Healthcare support staff: certified nursing assistants (certified nurse aide, state registered nurse aide), home health aides, patient aides, direct care professional, patient care technician, dental assistant, phlebotomist, resident assistant, residential youth worker, patient transporter; Community and Social Services: social worker, mental health and rehabilitation counselors, youth counselor, clergy/chaplain; Administrative: administrators, clerical/clerk, billing, receptionist; Other: housekeeping, maintenance (building and grounds), laundry services, kitchen staff (dietary aide, cook) 
Table 2. Injury characteristics of healthcare worker injuries by patient contact status, in Kentucky 20122014

\begin{tabular}{|c|c|c|c|c|c|c|}
\hline \multirow{2}{*}{$\begin{array}{l}\text { Injury } \\
\text { Characteristics } \\
\text { Nature of Injury }\end{array}$} & \multirow[t]{2}{*}{$\begin{array}{l}\text { Total } \\
\text { Injuries }\end{array}$} & \multicolumn{2}{|c|}{$\begin{array}{l}\text { Healthcare Injury } \\
\text { involved in direct } \\
\text { patient contact }\end{array}$} & \multicolumn{2}{|c|}{$\begin{array}{l}\text { Healthcare injury } \\
\text { without direct } \\
\text { patient contact }\end{array}$} & \multirow[t]{2}{*}{$p$-value ${ }^{a}$} \\
\hline & & $\#$ & $(\%)$ & $\#$ & $(\%)$ & \\
\hline Sprain or tear & 5671 & 3345 & $(66)$ & 2326 & (38) & $<.0001$ \\
\hline Fracture & 388 & 62 & (1) & 326 & (5) & \\
\hline Laceration or puncture & 1191 & 439 & (9) & 752 & $(12)$ & \\
\hline Contusion & 1876 & 545 & $(11)$ & 1331 & $(22)$ & \\
\hline Burn & 156 & $<5$ & $(<1)$ & 155 & $(2)$ & \\
\hline Multiple injuries & 321 & 85 & $(2)$ & 236 & (4) & \\
\hline Other & 501 & 149 & (3) & 352 & (6) & \\
\hline Not specified & 923 & 382 & (8) & 541 & (9) & \\
\hline No injury reported & 177 & 51 & (1) & 126 & $(2)$ & \\
\hline Total & 11,204 & 5059 & & 6145 & & \\
\hline \multicolumn{7}{|l|}{ Cause of Injury } \\
\hline Lifting/Handling & 3713 & 2654 & $(52)$ & 1059 & (17) & $<.0001$ \\
\hline Fall/slip/trip & 2605 & 215 & (4) & 2390 & (39) & \\
\hline Motor Vehicle Accident & 387 & 8 & $(<1)$ & 379 & (6) & \\
\hline Struck by person & 881 & 848 & (17) & 33 & $(<1)$ & \\
\hline $\begin{array}{l}\text { Struck by object or } \\
\text { animal }\end{array}$ & 1677 & 536 & (11) & 1141 & (19) & \\
\hline Thermal & 175 & 15 & $(<1)$ & 160 & (3) & \\
\hline Caught in something & 281 & 74 & $(1)$ & 207 & (3) & \\
\hline No physical injury & 267 & 92 & $(2)$ & 175 & (3) & \\
\hline Not Specified & 1218 & 617 & (12) & 601 & (10) & \\
\hline Total & 11,204 & 5059 & & 6145 & & \\
\hline \multicolumn{7}{|l|}{ Body Part Injured } \\
\hline Head (including face) & 788 & 338 & (7) & 450 & (7) & $<.0001$ \\
\hline Neck & 164 & 81 & (2) & 83 & (1) & \\
\hline Back & 2437 & 1708 & (34) & 729 & (12) & \\
\hline Trunk & 470 & 266 & (5) & 204 & (3) & \\
\hline Upper extremity ${ }^{b}$ & 3480 & 1596 & (32) & 1884 & (31) & \\
\hline Lower extremityc & 2161 & 519 & (10) & 1642 & $(28)$ & \\
\hline Multiple body parts & 1385 & 457 & (9) & 928 & (15) & \\
\hline Non-musculoskeletal & 60 & 16 & $(<1)$ & 44 & $(<1)$ & \\
\hline No physical injury & 78 & 14 & $(<1)$ & 64 & (1) & \\
\hline Not identified & 181 & 64 & (1) & 117 & $(2)$ & \\
\hline Total & 11,204 & 5059 & & 6145 & & \\
\hline
\end{tabular}

${ }^{a} p$-value based on chi-square

bupper extremity: Arm, shoulder, elbow, wrist, hand, finger, thumb

'Lower extremity: Hip, leg, quadriceps, hamstring, knee, ankle, foot, toe 
Table 3. Time and place of healthcare injuries by patient contact status, in Kentucky 2012-2014

\begin{tabular}{|c|c|c|c|c|c|c|}
\hline \multirow{2}{*}{$\begin{array}{l}\text { Injury by location and time of year } \\
\text { Facility Type }\end{array}$} & \multirow[t]{2}{*}{$\begin{array}{l}\text { Total } \\
\text { Injuries }\end{array}$} & \multicolumn{2}{|c|}{$\begin{array}{l}\text { Injury involved } \\
\text { direct patient } \\
\text { contact }\end{array}$} & \multicolumn{2}{|c|}{$\begin{array}{l}\text { Injury without } \\
\text { direct patient } \\
\text { contact }\end{array}$} & \multirow[t]{2}{*}{$p$-value ${ }^{a}$} \\
\hline & & $\#$ & $(\%)$ & $\#$ & $(\%)$ & \\
\hline General Medical \& Surgical Hospital & 3459 & 1393 & (28) & 2066 & (34) & $<.0001$ \\
\hline Psychiatric and Substance Abuse Hospitals & 368 & 231 & (5) & 137 & (2) & \\
\hline Nursing Care Facilities & 3671 & 1967 & (39) & 1704 & (28) & \\
\hline Continuing Care Retirement Communities & 716 & 372 & (7) & 344 & (6) & \\
\hline Home Health Care Services & 977 & 380 & (8) & 597 & (8) & \\
\hline $\begin{array}{l}\text { Offices of Practitioners (non-mental } \\
\text { health) }\end{array}$ & 905 & 302 & (6) & 603 & (10) & \\
\hline Offices of Mental Health Practitioners & 53 & 19 & $(<1)$ & 34 & $(<1)$ & \\
\hline Medical Laboratories & 133 & 15 & $(<1)$ & 118 & (2) & \\
\hline \multirow[t]{2}{*}{ Other } & 922 & 380 & (8) & 542 & (9) & \\
\hline & 11,204 & 5059 & & 6145 & & \\
\hline \multicolumn{7}{|l|}{ Region of Injury } \\
\hline \multirow[t]{2}{*}{ Appalachian Region } & 3005 & 1359 & (27) & 1646 & (27) & \\
\hline & & 3676 & (73) & 4460 & (73) & $<.0001$ \\
\hline Non-Appalachian Region & 8136 & 24 & $(<1)$ & 39 & $(<1)$ & \\
\hline Out of State & 63 & & & & & \\
\hline \multicolumn{7}{|l|}{ Month of Injury } \\
\hline January & 963 & 397 & (8) & 566 & (9) & \\
\hline February & 940 & 410 & (8) & 530 & (9) & $<.0001$ \\
\hline March & 932 & 428 & (9) & 504 & (8) & \\
\hline April & 848 & 371 & (7) & 477 & (8) & \\
\hline May & 963 & 446 & (9) & 517 & (8) & \\
\hline June & 942 & 408 & (8) & 534 & (8) & \\
\hline July & 952 & 430 & (9) & 522 & (9) & \\
\hline August & 1047 & 470 & (9) & 577 & (9) & \\
\hline September & 1002 & 448 & (9) & 554 & (9) & \\
\hline October & 1008 & 502 & (10) & 506 & (8) & \\
\hline November & 815 & 358 & (7) & 457 & (7) & \\
\hline \multirow[t]{2}{*}{ December } & 792 & 391 & (8) & 401 & (7) & \\
\hline & 11,204 & 5059 & & 6145 & & \\
\hline
\end{tabular}

${ }^{a} p$-value based on chi-square 
Table 4. Injury scenarios for injuries involved in direct patient contact among all occupations.

\author{
Nature of Injury \\ Sprain $(n=3,345)$ \\ "Pulling patient in bed and hurt lower back" \\ "Transferring patient from wheelchair to bed, felt pain strain left shoulder, armpit, rotator cuff" \\ "Back strain, assisting patient out of car in ER" \\ Contusion ( $n=545)$ \\ "Struck by combative patient" \\ "Employee positioning resident in bed. Employee lifted resident's leg and it reflexed out and kicked \\ employee in her right knee." \\ "Contusion/head/restraining client, kicked in head"

\section{Laceration or Puncture $(\mathrm{n}=\mathbf{4 3 9})$} \\ "First finger on left hand, finger stuck while drawing blood, dirty needlestick" \\ "Performing surgery making incision scalpel slipped he caught it and cut his left index finger" \\ "Shaving a resident, resident tried to get razor causing the injured worker to cut herself on lower \\ arm" \\ Cause of Injury \\ Lifting/Handling ( $n=2654)$ \\ "The employee was assisting another staff member with loading a patient from the wheelchair" \\ "Employee strained right arm as transferring patient" \\ "Employee was helping a resident back to bed and strained lower back"

\section{Struck by person $(n=848)$} \\ "Employee was providing patient care the patient reached up and scratched her on the face" \\ "Employee was punched in right eye by combative patient" \\ "Employee was trying to put patient's oxygen back on his face when patient grabbed her right wrist \\ and twisted it"

\section{Struck by object $(n=536)$} \\ "Right thumb needle stick. Performing a punch biopsy while performing procedure and manipulating \\ punch biopsy she was nicked on her right thumb" \\ "Injury/shoulder/ aggressive client threw chair hitting claimant in right shoulder" \\ "Injured worker was drawing blood from infant for culture when punctured left hand with \\ contaminated needle"
}


Table 5. Injury scenarios for injuries not Involved in direct patient contact for all occupations.

\begin{tabular}{|c|}
\hline Nature of Injury \\
\hline $\begin{array}{l}\text { Sprain ( } \mathbf{n}=\mathbf{2 3 2 6} \text { ) } \\
\text { "Pulling cart of food my shoulder popped lifting pans into fridge" } \\
\text { "Emptying garbage dumpster, cart fell in compactor and tried to pull it out" } \\
\text { "Employee tripped and fell on patient's steps; sprained right wrist" }\end{array}$ \\
\hline $\begin{array}{l}\text { Contusion (n=1331) } \\
\text { "Contusion/multiple right side/ employee slipped on kitchen floor and fell landing on her right side" } \\
\text { "Employee was exiting the freezer smashing left middle finger in the door" } \\
\text { "Going to get trash out of trash can and tripped over chair" }\end{array}$ \\
\hline $\begin{array}{l}\text { Laceration ( } \mathbf{n = 7 5 2 )} \\
\text { "Employee cut finger on unidentified object" } \\
\text { "Injured worker cut her left hand on a knife in the kitchen" } \\
\text { "Employee was cleaning up after surgical procedure. Employee reached for scalpel and cut left } \\
\text { forefinger" }\end{array}$ \\
\hline Cause of Injury \\
\hline $\begin{array}{l}\text { Fall/slip/trip ( } \mathbf{n = 2 3 9 0 )} \\
\text { "Slipped and fell while waxing floor" } \\
\text { "After stepping out of the back of the ambulance, the employee felt a pop in her left knee" } \\
\text { "Employee tripped and fell over cord" }\end{array}$ \\
\hline $\begin{array}{l}\text { Lifting/handling ( } \mathbf{n}=\mathbf{1 0 5 9 )} \\
\text { "Lifting radiology equipment it slipped and crushed finger" } \\
\text { "Pulling dirty linen from cart and strained upper back" } \\
\text { "Lifting mattress to clean and felt pain in neck" }\end{array}$ \\
\hline $\begin{array}{l}\text { Struck by object or animal ( } \mathbf{n}=\mathbf{1 1 4 1}) \\
\text { "Placing syringe into sharp container needle popped out of sharp container sticking staff" } \\
\text { "Dog bit employee on right hand" } \\
\text { "Lowered bath tub and tried to move lift and it was stuck, when it moved it lowered and slammed on } \\
\text { left foot" }\end{array}$ \\
\hline
\end{tabular}


Figure 1. Reported incidence rates among clinical occupations in Kentucky 2012-2014.

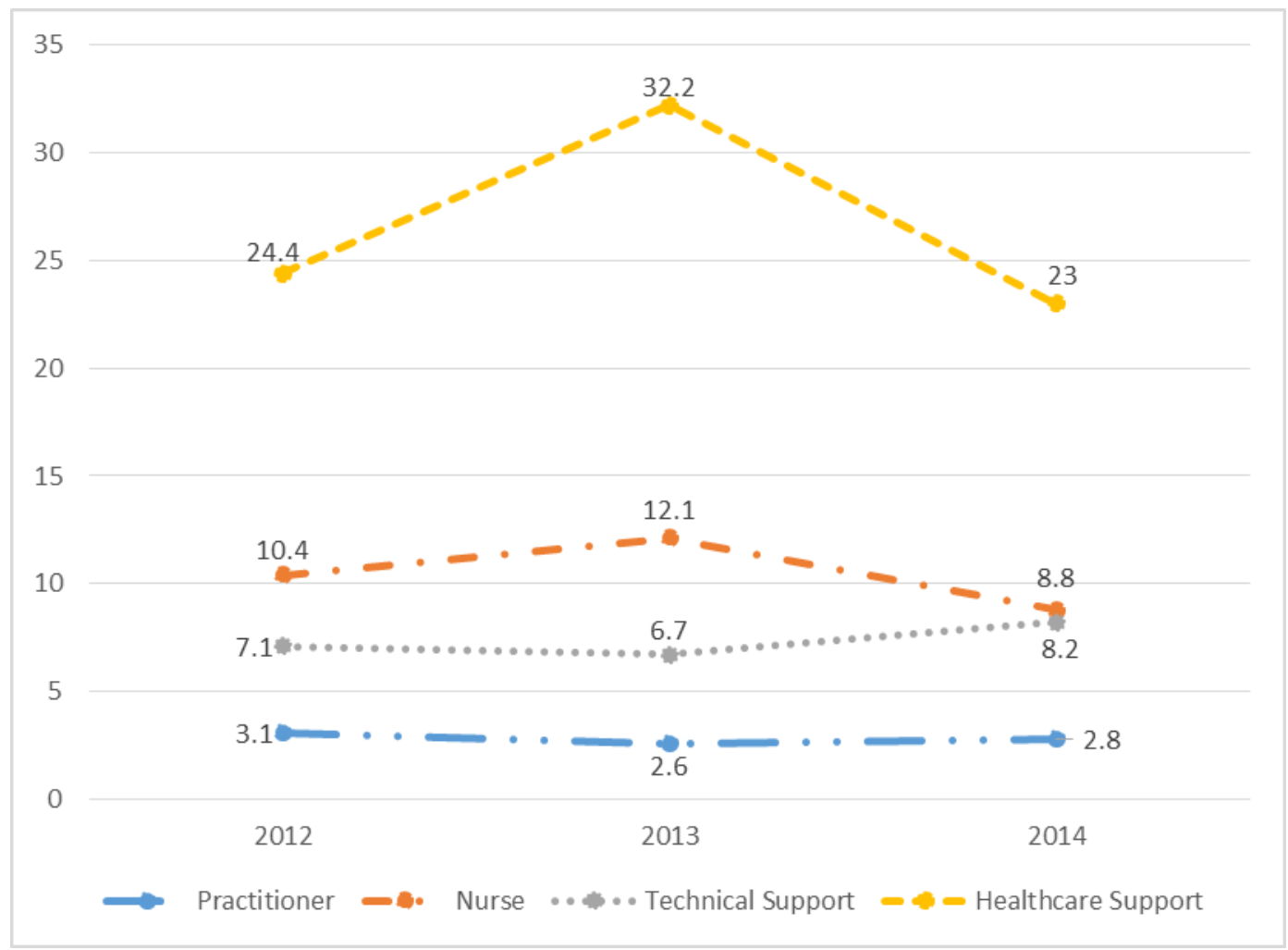




\section{References}

1. America's Hosptials: Improving Quality and Safety - The Joint Commission's Annual Report 2014. Available from:

http://www.jointcommission.org/assets/1/18/TJC Annual Report 2014 FINAL.pdf

2. Bureau of Labor Statistics, U.D.o.L. News Release: Workplace Injuries and IIInesses - 2010. 20

October 2011: Available from: http://www.bls.gov/news.release/archives/osh 10202011.pdf page=13.

3. Occupational Safety and Health Administration, U.S.D.o.L. Safety and Health Topics: Healthcare. 24 September 2015; Available from:

https://http://www.osha.gov/SLTC/healthcarefacilities/index.html.

4. H J Lipscomb, A.L.S., D J Myers, L A Pompeii, J M Dement, Evaluation of direct workers' compensation costs for musculoskeletal injuries surrounding interventions to reduce patient lifting. Occupational Environmental Medicine, 2012. 69: p. 367-372.

5. Janet Mayeda-Letourneau, P., MHA, Safe Patient Handling and Movement: A literature review. Rehabilitation Nursing, 2014. 39: p. 123-129.

6. Bureau of Labor Statistics, U.D.o.L. News Release: Nonfatal occupational injuries and illnesses requiring days away from work. 16 December 2014: Available from:

http://www.bls.gov/news.release/archives/osh2 12162014.pdf.

7. NIOSH. Stop Sticks Campaign. 24 September 2015; Available from: http://www.cdc.gov/niosh/stopsticks/sharpsinjuries.html - epinet.

8. Nonika Rajkumari, B.T., Nibu Varghese John, Jacinta Gunjiyal, Purva Mathur, Mahesh Chandra Misra, A prospective look at the burden of sharps injuries and splashes among trauma health care workers in developing countries: True picture or tip of iceberg. Injury: International Journal of the Care of the Injured, 2014. 45(9): p. 1470-1478.

9. Pia Markkanen, C.G., Angela Laramie, June Fisher, Susan Sama, Margaret Quinn, Understanding sharps injuries in home healthcare: The Safe Home Care qualitative methods study to identify pathways for injury prevention. BMC Public Health, 2015. 15(359): p. 12.

10. Bureau of Labor Statistics, U.D.o.L. Sate Occupational Employment and Wage Estimates Kentucky. Available from: http://www.bls.gov/oes/current/oes ky.htm.

11. Nancy I. Thomas, P., APN, COHN-S, RPSGT, Norman D. Brown, EdD, FNP, Linda C. Hodges, EdD, Jay Gandy, PhD, Louanne Lawson, PhD, Janet E. Lord, PhD, David K. Williams, PhD, Risk Profiles for Four Types of Work-Related Injury among Hospital Employees A Case-Control Study. American Association of Occupational Health Nurses, 2006. 54(2): p. 61-68.

12. Sarah M Ketelaar, K.N., Monique H W Frings-Dresen, Judith K Sluiter, Exploring novice nurses' needs regarding their work-related health; a qualitiative study. International Archives of Occupational and Environmental Health, 2015. 88(7): p. 953-962.

13. Occupational Safety and Health Administration, U.S.D.o.L. Memorandum for Regional Administrators: Inspection Guidance for Inpatient Healthcare Settings. 24 September 2015; Available from: http://www.osha.gov/dep/enforcement/inpatient insp 06252015.html.

14. Hyun Kim, S., Jonathan Dropkin, PT, MS, Kenneth Spaeth, MD, MPH, Francine Smith, BA, Jacqueline Moline, MD, MSc, Patient Handling and Musculoskeletal Disorders Among Hospital Workers: Analysis of 7 Years of Institutional Workers' Compensation Claims Data. American Journal of Industrial Medicine, 2011. 55: p. 683-690.

15. Hasanat Alamgir, S.Y., Negar Chavoshi, Karen Ngan, Occupational injury among full-time, parttime and casual health care workers. Occupational Medicine, 2008. 58: p. 348-354.

16. H Alamgir, Y.C., S Yu, A Yassi, Work-related injury among direct care occupations in British Columbia, Canada. Occupational Environmental Medicine, 2007. 64: p. 769-775. 
17. Bureau of Labor Statistics, U.D.o.L. Occupational Outlook Handbook. [cited 2015]; Available from: http://www.bls.gov/ooh/Healthcare/Nursing-assistants.htm - tab-3.

18. Cathy Voide, K.E.A.D., Alain Kenfak-Foguena, Veronique Erard, Matthias Cavassini, Catherine Lazor-Blanchet, Underreporting of needlestick and sharps injuries among healthcare workers in a Swiss Universtiy Hospital. Swiss Medical Weekly, 2012. 142(w13523).

19. Kurt Vaz, D.M., Tazhmoye Crawford, Ruby Lisa Alexander-Lindo, and Rachael Irving, Prevalence of Injuries and Reporting of Accidents Among Health Care Workers at the Universtiy Hospital of the West Indies. International Journal of Occupational Medicine and Environmental Health, 2010. 23(2): p. 133-143.

20. Jennifer L. Bell, J.W.C., Laurie Wolf, Raoul Gronqvist, Sharon Chiou, Wen-Ruey Chang, Gary S. Sorock, Theodore K. Courtney, David A. Lombardi, Gradley Evanoff, Evaluation of a comprehensive slip, trip and fall prevention programme for hospital employees. Ergonomics. 15(12): p. 1906-1925.

21. Terry Kowalenko MD, D.G.E., Gordon Lee Gillespie PhD, Paul Succop PhD, Tammy K Mentzel, Prospective study of violence against ED workers. The American Journal of Emergency Medicine, 2013. 31: p. 197-205. 